I.К. Шаша ${ }^{1}$, I.В. Рогозін ${ }^{2}$, С.М. Новічонок ${ }^{2}$

${ }^{1}$ Начіональна академія Начіональної гвардї Украӥни, Харків

${ }^{2}$ Харківський національний університет Повітряних Сил ім. I. Кожедуба, Харків

\title{
МАТЕМАТИЧНІ МЕТОДИ ОЦІНКИ ЕКСПЛУАТАЦІЙНОЇ НАДІЙНОСТІ ЗАСОБІВ РУХОМОСТІ ОЗБРОЄННЯ ТА ВІЙСЬКОВОЇ ТЕХНІКИ
}

У статті наводяться результати дослідження безвідмовності засобів рухомості (ЗР) озброєння та військової техніки (OBT) по напрацююванню і витратам енергї̈, встановлено кореляційний зв'язок між ними та обтрунтовано доцільність планування технічних обслуговувань і ремонту по пробігу.

Ключові слова: безвідмовність, відмова, довговічність, засіб рухомості, надійність, озброєння та військова техніка, технічне обслуговування

\section{Вступ}

Постановка проблеми. Особливості ведення сучасних бойових дій, збройні конфлікти на територіях інших країн, проведення АТО та ООС на сході нашої держави, вказують на вирішальну роль мобільності зразка ОВТ та військ в цілому.

На зразок ОВТ можуть впливати велика кількість чинників, у тому числі й можлива відмова засобу рухомості (автомобільного шасі, що забезпечує пересування, на якому змонтовано спеціальне обладнання). В свою чергу, на інтенсивність потоків відмов (несправностей) і відновлення ЗР, в умовах ведення бойових дій також впливає велика кількість факторів, що обумовлює їх перехід у той чи інший стан. Потік відмов формується 3 двох основних потоків: відмови від бойових пошкоджень (впливу противника) і відмови 3 експлуатаційних причин (неправильний вибір експлуатаційних режимів, знос агрегатів та деталей тощо). Типові методи розрахунку надійності не повному обсязі враховують можливі нештатні ситуації та інші фактори, що виникають під час експлуатації, у тому числі при ведення бойових дій (в бойових умовах) [1].

В той же час, поширення застосування в сучасних автомобілях електричних та гібридних силових агрегатів, різноманітних систем активної безпеки, діагностики стану, інших електричних та електронних приладів потребує застосування бортової системи електронного керування (в перспективі інтелектуального керування) [2-4]. Тому провідні світові виробники постійно вдосконалюють автомобілі, у тому числі ЗР ОВТ, в частині їх комплектування бортовими системами електронного керування що мають функції збору інформації та управління системами, які забезпечують його безпечну та ефективну експлуатацію (безпеку руху, інформування про відмови 3 експлуатаційних причин, залишок напрацювання до чергового технічного обслуговування та ремонту тощо). Проте зміни умов експлуатації (інтенсивність навантаження на окремі деталі та агрегати) та їх влив на необхідність проведення технічного обслуговування (ремонту) в таких системах, як правило не враховуються [1-5].

Аналіз останніх досліджень і публікацій. Аналіз проведених досліджень показує, що дослідженню надійності та їі забезпеченню в автомобільній техніці завжди приділялася значна увага [1-9].

Відмови ЗР ОВТ з експлуатаційних причин відбуваються на всіх етапах циклу, у тому числі на етапах зберігання, експлуатації і відновлення. В той же час, досліджень щодо прогнозування відмови автомобіля $з$ експлуатаційних причин, а саме через зміну інтенсивності навантаження на його окремі деталі та агрегати в роботах, які були проаналізовані, проведено не було [1; 5-10].

Відомо що істотний вплив на безвідмовність ЗР ОВТ чинять умови експлуатації [5; 7-8]. В цілому умови експлуатації в рамках спектральної теорії випадкових функцій найбільш повно характеризуються такими параметрами [5; 7-8].

- функцією математичного очікування:

$$
\bar{X}(t)=\frac{1}{n} \sum x_{i}(t) ;
$$

- дисперсією процесу:

$$
D_{x}(t)=\sum[x(t)-\bar{x}(t)]^{2} / n-1 ;
$$

- кореляційної функцією:

$k_{x}\left(t_{k}, t_{i}\right)=\sum\left[x\left(t_{k}\right)\right] \cdot\left[x\left(t_{i}\right)-\bar{x}\left(t_{i}\right)\right] / n-1 ;$

- нормованої кореляційної функцією:

$$
P_{X}(\tau)=\frac{k_{X}(\tau)}{\sqrt{D_{X}\left(t_{k}\right) D_{X}\left(t_{e}\right)}} ;
$$

- спектральною щільністю процесу:

$$
S(\omega)=\frac{1}{2 \pi} \int_{-\infty}^{\infty} P_{X}(\tau) e^{-i \omega \tau} d \tau,
$$


де $n$ - число реалізацій;

$x_{i}(t)$ - значення процесу в перетині $t$;

$t_{k}, t_{e}$ - перетини процесу в моменти $\mathrm{K}, \mathrm{e}$;

$\tau$ - інтервал процесу між розглянутими перетинами;

$w$ - частота процесу;

$P_{X}(\tau) e^{-i w \tau}-$ інтегральне перетворення Фур'є.

Оскільки досліджувані параметри формуються під впливом спектру випадкових факторів на підставі центральної граничної теореми теорії ймовірностей, їх розподіл в кожному перетині процесу може бути прийнято нормальним з щільністю розподілу:

$$
f(x)=\frac{1}{\sigma \sqrt{2 \pi}} e^{\frac{-(x-\bar{x})}{2 \sigma^{2}}},
$$

де $\bar{x}, \sigma$ - математичне очікування і середньоквадратичне відхилення випадкової величини.

Для визначення кількості відмов за час $t$ зовнішні навантаження представляють у формі деякого процесу $P^{e}(t)$ тривалості $t$. Деякі дослідники вважають, що для визначення кількості відмов внаслідок досягнення або перевищення зовнішнього навантаження за час $\mathrm{t}$ необхідно встановити рівень міцності його конструкції $P_{i}^{p}$ (функція номера $\mathrm{i}-$ випадкова величина), викид енергії за цей рівень відповідає процесу руйнування [8].

Рішення даного завдання є актуальним, оскільки дозволить підвищити комплексні показники надійності [11] (коефіцієнт готовності, коефіцієнт технічного використання тощо) ЗР та рівень готовності до застосування за призначенням зразка ОВТ в цілому.

Метою статті $\epsilon$ теоретичне визначення забезпечення ресурсу за критерієм одиничного допустимої відмови на основі ймовірнісної моделі опору втоми елементів конструкції та даних, які отримуються в реальних умовах експлуатації.

\section{Виклад основного матеріалу}

Постановка завдання. Ймовірносностатистичні методи регламентування надійності роботи ЗР та зразка ОВТ в цілому засновані на тому, що існує певний зв’язок між надійністю конструкції і рівнем розрахункових навантажень [6]. Це дозволяє для заданого рівня надійності визначати відповідний рівень розрахункових навантажень. Поява відмов можна уявити як факт досягнення або перевищення зовнішнього навантаження відповідно до витрат енергії двигуном.

Вирішення завдання дослідження зводиться до визначення числа відмов за витратами енергії в конкретних умовах експлуатації.

Для визначення максимального значення від- мов приймаємо:

- якщо $P_{i \max }^{e} \geq P_{i}^{p}$, то має місце руйнування;

- якщо $P_{i \text { max }}^{e} \leq P_{i}^{p}$, то руйнування немає.

Звідси випливає, що для підрахунку ймовірності руйнування конструкції необхідно визначити ймовірність нерівності, що функція розподілу максимальних величин зовнішніх навантажень залежить від витрат енергії двигуна. Такий підхід до визначення величини ймовірності руйнування може бути використаний при будь-якій формі розподілу відмов (дискретне або безперервне опис зовнішніх навантажень). Форми розподілів відмов при малих можливостях зовнішніх навантажень і несучих здібностей агрегатів на величину ймовірності руйнування вважається одним 3 головних недоліків ймовірносно-статистичних методів розрахунку. Це можна показати за допомогою оцінки, отриманої для значень функції розподілу різниці двох випадкових величин за допомогою відомих значень функції розподілу $f_{x}(a)$ i $f_{y}(b)$ в точках $x=a$ та $y=b$ (за умови, що $z=c), z=x-y$ :

$$
f_{X}(a)\left[1-f_{y}(b)\right]<f_{x}(c)<1-f_{y}(b)\left[1-f_{X}(a)\right] .
$$

Під час експлуатації надійність конкретного ЗР невідома через те, що технічні обслуговування (ремонт) проводяться по напрацюванню, яке вимірюється часом знаходження в експлуатації або пробігом від чергового технічного обслуговування, а не фактичним станом. Під час ремонту агрегату (вузла, збірної одиниці, системи), що вийшов з ладу, деталі, які стоять поряд 3 теми, що відмовили, й можливо знаходяться на грані зносу не замінюються через те, що за зовнішнім виглядом вони справні. Ці фактори приводять до збільшення кількості технічних обслуговувань (ремонтів), що у свою чергу, збільшує ймовірність несправності (наприклад, за виною персоналу, що виконує технічне обслуговування або ремонт) [1; 7; 9-10].

В даний час розглядаються три способи забезпечення надійності за умовами опору утоми деталей:

- встановлення безпечного ресурсу;

- забезпечення ресурсу за принципом безпечного або допустимого ушкодження з частковим обмеженням ресурсу;

- експлуатація без обмеження ресурсу.

Принцип безпечного ресурсу встановлюється до деталей, циклічні пошкодження яких призводить, як правило, до руйнування всього агрегату і не може бути своєчасно в експлуатації при періодичних обслуговуваннях. При цьому допустима довговічність обмежується величиною безпечного ресурсу як для 
парку автомобілів в цілому, так і для окремих екземплярів при індивідуальній оцінці умов експлуатації.

Принцип допустимого ушкодження (забезпечення експлуатаційної живучості) застосовується для ЗР ОВТ, агрегатів або деталей, поява втомних пошкоджень яких не призводить до миттєвого руйнування конструкції в цілому і може бути виявлено при проведенні технічних обслуговувань або ремонтів.

Методи розв'язання задачі. Оскільки основним завданням безпечного ресурсу є недопущення руйнувань в експлуатації, то представляється можливим за критерій надійності прийняти реальну ймовірність відсутності пошкодження, яка може бути визначена за витратами енергії наступним чином.

Нехай ймовірність відсутності пошкодження конструкції є деякою функцією ресурсу, вираженого числом циклів дії змінних зовнішніх навантажень, тоді функція розподілу до руйнування конструкції дорівнює:

$$
\stackrel{\approx}{B}=1-F\left(N_{u}\right)
$$

де $F\left(N_{u}\right)=\int_{-\infty}^{N} f(o) d_{o}-$ інтегральний розподіл довговічності за кількістю циклів $N_{u}$ навантаження.

Дії змінних зовнішніх навантажень для різних зразків ОВТ можуть бути різні. Так, наприклад, для 3Р аеродромно-технічного забезпечення польотів авіації під час ведення бойових дій це можуть бути $[1 ; 10 ; 12]$ :

- рух під час перебазування (особливо рух поза дорогами тощо);

- використання зразка в якості тягача (буксирування літаків, інших несправних ЗР аеродромнотехнічного забезпечення польотів авіації тощо)

- використання не за призначенням у випадку необхідності швидкого відновлення боєздатності аеродрому.

Ймовірність того, що одна деталь агрегату або вузла не зруйнується під час експлуатації протягом встановленого терміну, може бути записана у вигляді:

$$
\tilde{\widetilde{B}}=\int_{-\infty}^{\infty}\left[1-F\left(N_{u}\right)\right] f_{d}\left(N_{u}\right) d N_{u},
$$

де $f_{d}\left(N_{u}\right)$ - щільність ймовірності припустимого ресурсу за результатами втомного випробування.

На кожному ЗР ОВТ є велика кількість однотипних деталей (підшипники, кріпильні з’єднання, зубчасті передачі, гальмівні накладки тощо). Позначимо ці деталі символом $\mu$. Тоді ймовірність цілісності деталей та агрегатів ЗР ОВТ дорівнює:

$$
\widetilde{\tilde{B}}_{M}=\int_{-\infty}^{\infty}[1-F(x)]^{\mu} f_{d}\left(N_{u}\right) d N_{u} .
$$

Величину доцільно взяти за основний критерій надійності ЗР ОВТ за умовами опору втоми, так як ця величина має поруч необхідних властивостей:

1. Рівняння (8) дає однозначну зв'язок між величиною і запасом довговічності при встановленні ресурсу. Якщо термін служби встановлюється відношенням результату випробувань на коефіцієнт надійності ๆ, тоді:

$$
\widetilde{\widetilde{B}}_{M}=\int_{-\infty}^{\infty}\left[1-F\left(\frac{N_{u}}{3}\right)\right]^{\mu} f_{d}\left(N_{u}\right) d N_{u} .
$$

2. Величина $\tilde{B}_{м}$ являє собою ймовірність того, що весь парк ЗР ОВТ даної марки не буде мати жодного пошкодження (відмови) за період експлуатації. Тому величина повинна бути призначена настільки високою, щоб руйнування хоча б одного автомобіля з усього парку було практично неможливо.

3. Критерій $\approx_{B_{M}} є$ досить гнучким, він дозволяє враховувати особливості законів розподілу, спосіб встановлення терміну служби кожного елемента конструкції. Наприклад, закон розподілу довговічності $F\left(N_{u}\right)$ є порівняно слабо зростаючою функцією при малих ймовірностях і функція $f_{d}$ займає досить вузький діапазон довговічності (що відповідає випадку великої кількості зразків при випробуваннях на втому), в рівнянні (9) можна прийняти $F\left(N_{u}\right)=$ const .

Перераховані властивості дозволяють вважати $\approx$

$B_{M}$ прийнятним критерієм оцінки ресурсу при різних величинах $N_{0}$. Для розглянутої задачі важливим $є$ співвідношення порогу чутливості, показує, що при достатньо великих значеннях порогу чутливості надійність визначається величиною довірчої ймовірності безпечного терміну служби ЗР ОВТ, тобто порогу чутливості втомної довговічності. Це дозволяє встановити кількісні величини запасів довговічності.

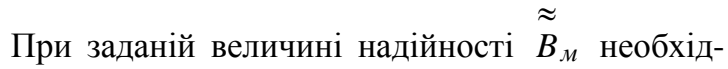
ний запас довговічності визначають рівнянням (8). Для значень величини $N_{O}$ близьких до величині середньої довговічності і великій кількості експлуатованих автомобілів, можна значно спростити розрахунки за визначенням потрібного запасу за коефіцієнтом надійності ๆ. Тоді уявімо термін служби деталей за результатами випробувань в такому вигляді: 


$$
N_{\text {дon }}=\tilde{\tilde{N}}_{0}-U_{H M} \cdot y_{\tilde{N}_{0}},
$$

$\approx$

де $N_{0}$ - оцінка середнього порога чутливості за результатами випробувань (експлуатації);

$U_{\text {нм }}$ - квантіль нормального розподілу, що відповідає ймовірності $\stackrel{\approx}{B_{M}}$;

$y_{\tilde{N}_{0}}$ - середньоквадратичне значення порогу чутливості деталі до руйнування.

Якщо термін служби встановлюється відношенням результату випробувань на коефіцієнт надійності $N_{\partial o n}=N_{H} / 3$, то в даному випадку $N_{H}=N_{0}$, отримаємо формулу для визначення потрібного запасу довговічності з урахуванням порога чутливості по циклам:

$$
3=\frac{1}{1-\frac{k_{1}}{\sqrt{n}} \frac{e^{n}}{N_{0}} U_{H M} e^{-y^{2}},}
$$

$$
\text { де } k_{1}=\frac{y_{N_{0}}}{\sqrt{y_{N_{0}}^{2}+1-0,5\left(4 y_{N_{0}}^{4}+y_{N_{0}}^{2}+2\right)} e^{-y_{N_{0}}^{2}}}
$$$$
n \text { - число ЗР ОВТ, що знаходяться під }
$$
наглядом.

\section{Висновки}

1. Результати проведених досліджень дозволили визначити, що математичну модель забезпечення ресурсу за критерієм одиночно допустимої відмови можна отримати на основі ймовірнісної моделі опору втоми елементів конструкції.

2. На основі даних, отриманих в реальних умовах експлуатації, можливо обчислити параметри потоку відмов. Так як $t_{r}>3$, то параметр потоку відмов обчислюється 3 гарантованою імовірністю більше 0,90 .

3. Наданий метод дозволяє (за умовою відомого значення кількості циклів $N_{u}$ навантаження) визначати надійність окремого агрегату (системи) та автомобіля в цілому.

Визначення кількості циклів $N_{u}$ навантаження ЗР ОВТ підчас використання за призначенням $є$ предметом подальших досліджень.

Таким чином, при розрахунку річних експлуатаційних витрат враховується кількість проведених технічних обслуговувань.

Нормативний термін проведення технічного обслуговування встановлюється на підставі статистичних даних, отриманих в конкретних умовах експлуатації, виходячи з трудомісткості одного обслуговування і усунення відмов.

Підтверджено справедливість судження, що в міру збільшення напрацювання питоме значення трудомісткості поточного ремонту зростає, а потім поступово знижується.

\section{Список літератури}

1. Салій А.Г. Методика визначення виходу з ладу автомобільної і електрогазової техніки в умовах ведення бойових дій. / А.Г. Салій, І.В. Рогозін, К.Г. Яценко // Системи озброєння і військова техніка. - 2012. - № 2(30). - С. 86-88.

2. Aleksiyev O. Development of automotive computer systems based on the virtualization of transportation processes management / O. Aleksiyev, V. Aleksiyev, D. Klets // Eastern-European Journal of Enterprise Technologies. - 2017.- № 6(90). - P. 14-25. https://doi: 10.15587/1729-4061.2017.116351.

3. Спосіб розрахунку основних параметрів гібридного силового агрегату для спеціалізованих автотранспортних засобів / І.В. Рогозін, С.М. Новічонок, А.В. Гнатов, А.І. Рогозіна // Автомобіль і Електроніка. - 2018. - № 13. - С. 5-12. https://doi: 10.30977/VEIT.2018.13.0.5.

4. Bobbie F. Using optimal control in concept evaluation and system optimization of diesel-electric hybrid construction machines. / F. Bobbie // International Conference on Electrical Systems for Aircraft, Railway, Ship Propulsion and Road Vehicles \& International Transportation Electrification Conference (ESARS-ITEC) - 2016. - P. 1-6.

5. Шаша И.К. Выбор критерия оценки эксплуатационной надежности автомобилей / И.К. Шаша, А.О. Иванченко, И.В. Рогозин // Збірник наукових праць Харківського університету Повітряних Сил. - 2014. - № 3(40) - С. 149-151.

6. Говорущенко Н.Я. Системотехника проектирования транспортных машин / Н.Я. Говорущенко, А.Н. Туренко. Х.: ХНАДУ, 2004. - $208 \mathrm{c}$.

7. Говорущенко Н.Я. Диагностика технического состояния автомобилей / Н.Я. Говорущенко. - М.: Транспорт, 1970. $-254 \mathrm{c}$.

8. Удосконалення математичної моделі зміни технічного стану автобронетанкової техніки / I.К. Шаша, А.О. Іванченко, В.О. Темніков, І.В. Цебрюк // Наука і техніка Повітряних Сил Збройних Сил України. - 2015. - № 4(21). - С. 138-142.

9. Рогозін І.В. Аналіз наслідків критичних відмов при ушкодженні пневматичної системи засобу рухомості / І.В. Рогозін, Д.М. Клец, В.А. Юхно // Збірник наукових праць Харківського університету Повітряних Сил. - 2015. № 3(44). - С. 80-84.

10. Рогозін І.В. Проблеми технічного обслуговування і ремонту засобів рухомості озброєння та військової техніки Повітряних Сил Збройних Сил України за технічним станом / І.В. Рогозін, О.Б. Куренко, С.М. Новічонок // Збірник наукових праць Харківського університету Повітряних Сил. - 2012. - № 3. - С. 150-152.

11. ДСТУ 2860-94. Надійність техніки. Терміни та визначення. - К., 2005. - 96 с.

12. Уроки війни на Сході. Уроки АТО: авіаційна компонента [Електронний ресурс] // Народна армія. - 2016. - Pежим доступу: http://veterano.com.ua/vijna/na-zakhysti-ukrainy/4696-uroki-vijni-na-skhodi-aviatsijna-komponenta. 


\section{References}

1. Saliy, A.H., Rohozin, I.V. and Yatsenko, K.G. (2012), "Metodyka vyznachennya vykhodu z ladu avtomobil'noyi i elektrohazovoyi tekhniky v umovakh vedennya boyovykh diy" [Methods of determining the failure of automotive and gas equipment in combat conditions], Systems of Arms and Military Equipment, No. 2(30), pp. 86-88.

2. Aleksiyev, O., Aleksiyev, V. and Klets, D. (2017), Development of automotive computer systems based on the virtualization of transportation processes management, Eastern-European Journal of Enterprise Technologies, No. 6(90), pp. 14-25. https://doi: 10.15587/1729-4061.2017.116351.

3. Rohozin, I.V., Novychonok, S.M., Hnatov, A.V. and Rohozina, A.I. (2018), "Sposib rozrakhunku osnovnykh parametriv hibrydnoho sylovoho ahrehatu dlya spetsializovanykh avtotransportnykh zasobiv" [Method for calculating the basic parameters of hy-brid power units for specialized vehicles], Avtomobil i elektronika, No. 13, pp. 5-12. https://doi: 10.30977/VEIT.2018.13.0.5.

4. Bobbie, F. (2016), Using optimal control in concept evaluation and system optimization of diesel-electric hybrid construction machines, International Conference on Electrical Systems for Aircraft, Railway, Ship Propulsion and Road Vehicles \& International Transportation Electrification Conference (ESARS-ITEC), pp. 1-6.

5. Shasha, I.K., Ivanchenko, A.O. and Rohozin, I.V. (2014), "Vybor kryteryya otsenky ekspluatatsyonnoy nadezhnosty avtomobyley" [Choose evaluation criteria operational reliability of the vehicle], Scientific Works of Kharkiv Air Force University, No. 3(40), pp. 149-151.

6. Govorushchenko, N.Ya. and Turenko, A.N. (2004), "Sistemotekhnika proyektirovaniya transportnykh mashin” [System engineering design of transport vehicles], KhNADU, Kharkiv, 208 p.

7. Govorushchenko, N.Ya. (1970), "Diagnostika tekhnicheskogo sostoyaniya avtomobiley" [Diagnostics of the technical condition of vehicle], Transport, Moscow, $254 \mathrm{p}$.

8. Shasha, I.K., Ivanchenko, A.O., Temnikov, V.O. and Tsebryuk, I.V. (2015), “Udoskonalennya matematychnoyi modeli zminy tekhnichnoho stanu avtobronetankovoyi tekhniky" [Improvement of mathematical model of change of technical condition of auto armored vehicles], Science and Technology of the Air Force of Ukraine, No. 4(21), pp. 138-142.

9. Rohozin, I.V., Klets, D.M. and Yuhno, V.A. (2015), "Analiz naslidkiv krytychnykh vidmov pry ushkodzhenni pnevmatychnoyi systemy zasobu rukhomosti” [Analysis of the consequences of critical failures in the damage of the pneumatic system of the mobility vehicle], Scientific Works of Kharkiv Air Force University, No. 3(44), pp. 80-84.

10. Rohozin, I.V., Kurenko, O.B. and Novychonok, S.M. (2012), "Problemy tekhnichnoho obsluhovuvannya i remontu zasobiv rukhomosti ozbroyennya ta viys'kovoyi tekhniky Povitryanykh Syl Zbroynykh Syl Ukrayiny za tekhnichnym stanom" [Problems of maintenance and repair of weapons mobility equipment and military equipment of the Air Force of the Armed Forces of Ukraine by technical condition], Scientific Works of Kharkiv Air Force University, No. 3, pp. 150-152

11. State Standart of Ukraine (2005), “2860-94. Nadijnist tehniki. Termini ta viznachennya” [2860-94. Dependability of technics. Terms and definitions], Kyiv, 96 p.

12. (2016), "Uroki viyni na Shodi. Uroki ATO: aviatsiyna komponenta” [Lessons re-lated to the similarity. ATO lessons: aviacian component], Narodna armiya, available at: www.veterano.com.ua/vijna/na-zakhysti-ukrainy/4696-uroki-vijni-naskhodi-aviatsijna-komponenta.

Надійшла до редколегї 31.03.2020

Схвалена до друку 14.04.2020

\section{Відомості про авторів:}

\section{Шаша Ігор Костянтинович}

доктор технічних наук професор

професор кафедри

Національної академії Національної гвардії України,

Харків, Україна

https://orcid.org/0000-0001-7549-3119

\section{Рогозін Ігор Віталійович}

кандидат технічних наук

старший науковий співробітник

старший викладач кафедри

Харківського національного університету

Повітряних Сил ім. I. Кожедуба,

Харків, Україна

https://orcid.org/0000-0003-4126-6705

\section{Новічонок Сергій Михайлович} кандидат технічних наук доцент старший науковий співробітник

Харківського національного університету

Повітряних Сил ім. І. Кожедуба,

Харків, Україна

https://orcid.org/0000-0003-1269-5797

\section{Information about the authors:}

\section{Ihor Shasha}

Doctor of Technical Sciences Professor

Professor of Department

of National Academy of National Guard of Ukraine,

Kharkiv, Ukraine

https://orcid.org/ 0000-0001-7549-3119

\section{Ihor Rohozin}

Candidate of Technical Sciences

Senior Research

Senior Lecturer of Department

of Ivan Kozhedub Kharkiv National

Air Force University,

Kharkiv, Ukraine

https://orcid.org/0000-0003-4126-6705

\section{Serhii Novychonok}

Candidate of Technical Sciences Associate Professor

Senior Research

of Ivan Kozhedub Kharkiv National

Air Force University,

Kharkiv, Ukraine

https://orcid.org/0000-0003-1269-5797 


\title{
МАТЕМАТИЧЕСКИЕ МЕТОДЫ ОЦЕНКИ ЭКСПЛУАТАЦИОННОЙ НАДЕЖНОСТИ СРЕДСТВ ПОДВИЖНОСТИ ВООРУЖЕНИЯ И ВОЕННОЙ ТЕХНИКИ
}

\author{
И.К. Шаша, И.В. Рогозин, С.М. Новичонок
}

В статье приводятся результаты исследования безотказности средств подвижности вооружения и военной техники (BВT) по наработке и расходу энергии которые позволяют контролировать их эксплуатационную надежность. Предметом исследования является прочесс изменения эксплуатационной надежности средств подвижности ВВТ. Целью статьи является теоретическое определение обеспечения ресурса по критерию единичного допустимого отказа на основе вероятностной модели сопротивления усталости элементов конструкции и данных которые получены в реальных условиях эксплуатации. В ходе исследования установлена корреляционная связь между наработкой и расходом энергии средств подвижности ВBT, а также обоснована целесообразность планирования технических обслужсиваний и ремонта по пробегу. Приведенные исследования базируются на вероятностно-статистических методах регламентирования надежности автомобиля. Результаты проведенных исследований показали, что математическую модель обеспечения ресурса по критерию одиночно допустимого отказа можно получить на основе вероятностной модели сопротивления усталости элементов конструкиии. На основе данных, полученных в реальных условиях эксплуатации, появляется возможность вычислить параметры потока отказов. Так, параметр потока отказов исчисляется с гарантированной вероятностью более 0,90. Предоставленный метод позволяет (при условии, что известны значения количества ииклов нагружения) определить надежность отдельного агрегата (системы) и средства подвижности в ияелом. Определение количества циклов нагрузки средств подвижности ВВТ во время использования по предназначению является предметом дальнейших исследований. Нормативный срок проведения технического обслужсивания устанавливается на основании статистических данных, полученных в конкретных условиях эксплуатации, исходя из трудоемкости одного обслуживания и устранения отказов. Подтверждена справедливость суждения, что по мере увеличения наработки удельное значение трудоемкости текущего ремонта возрастает, а затем постепенно снижается.

Ключевые слова: безотказность, отказ, долговечность, средство подвижности, надежность, вооружение и военная техника, техническое обслуживание

\section{THE MATHEMATICAL METHODS OF EVALUATION OF OPERATIONAL RELIABILITY OF ASSETS OF MOBILITY OF WEAPONS AND MILITARY EQUIPMENT}

\section{Shasha, I. Rohozin, S. Novychonok}

The article presents the results of the research of dependability of mobility assets (MA) of weapon and military equipment (WME) according to operating hours and energy consumption which allow to control their operational reliability. The subject of the study is the process of investigation of operational reliability of mobility assets of of weapon and military equipment. The purpose of the article is theoretical determination of the resource provision by the criterion of a single permissible failure on the basis of the probabilistic model of fatigue resistance of structural elements and data obtained under real operating conditions. The research established a correlation between operating hours and energy consumption of mobility assets of weapon and military equipment and justified the feasibility of planning maintenance and repair according to mileage. The given studies are based on probability-statistical methods of determination of car reliability. The results of the carried out researches showed that the mathematical model of resource provision by the criterion of the only one permissible failure can be obtained on the basis of the probabilistic model of fatigue resistance of structural elements. A possibility to calculate the parameters of the failure flow on the basis of the data obtained under real operation conditions is shown. Thus, the failure flow parameter is calculated with a guaranteed probability of more than 0.90 . The provided method allows, provided that the loading cycle count values are known, to determine the reliability of the individual unit (system) and the mobility means as a whole. Determination of the number of load cycles of of MA of WME during use as intended is the subject of further research. The normative maintenance period shall be established on the basis of statistical data obtained under specific operating conditions, on the basis of the labour-intensivity of the one maintenance or one fault elimination. The judgement has been confirmed that as the operating time increases, at the beginning the specific value of the labour-intensity of the current repair increases and then gradually decreases.

Keywords: reliability, failure, durability, dependability, mobility assets, repair , weapons and military equipment, maintenance, mileage 